\title{
A New Approach to Laboratory-Based Learning in an Introductory Ergonomics Course
}

\author{
Kim Graves Wolfinbarger \\ The University of Oklahoma, Norman, OK
}

\begin{abstract}
Laboratory-based learning plays an important role in the introductory Ergonomics course at the University of Oklahoma. Qualitative analyses of technical reports over several semesters revealed repeated problems. Students were unfamiliar with academic publications, did not know how to report results, and had difficulty interpreting results. In addition to these problems, other difficulties arose. Students felt overwhelmed. Some developed a dislike for the field of human factors. Several cited the labs as the source of their dissatisfaction. To address these problems, we adopted a new approach to conducting the laboratory portion of the course. We sought to increase student engagement, support learning through scaffolding, increase the rate and quantity of feedback, and provide team-development opportunities. Students' performance in data analysis and technical writing improved over the previous year and throughout the semester. Satisfaction with the course as a whole and the laboratory section in particular improved. We are pleased with the results and plan to continue refining the course design. We hope that this article will inspire discussion of effective techniques in ergonomics laboratory instruction.
\end{abstract}

Laboratory-based learning plays an important role in the introductory Ergonomics course offered by the School of Industrial Engineering at the University of Oklahoma (OU). In addition to providing students the opportunity to gain experience with ergonomics methods, the lab exercises are designed to simulate activities typical of professional industrial engineering practice. This helps students understand the role of ergonomics in a systems context.

For many years, the Ergonomics course followed the same format. Students attended lectures three hours per week and attended laboratory sessions on alternating weeks. Working in teams, students conducted five experiments and presented the results in the form of technical reports and executive summaries.

Qualitative analyses of the reports over several semesters revealed repeated problems. First, students were unfamiliar with academic publications and the concept of a peer-reviewed journal. They could search Google and Wikipedia for answers, but they did not know how to use campus library resources to find research articles. If they did find a relevant article, they usually did not know how to summarize the results and apply them to their own experiments.

Second, students did not know how to report results. Their papers often lacked summary statistics. Figures and tables frequently stood alone, with no accompanying explanation in the text.

Third, students had great difficulty analyzing their results. Incorrect interpretations of data were frequent, and students struggled to explain the reasons for and the applicability of results obtained in their experiments.

Finally, the papers often lacked cohesion. Students would assign the writing of each section to a different group member. As a result, the problem statement, results, and discussion did not follow a logical flow. In some cases, the discussion even contradicted the reported results.

Quantitative measures also indicated problems. In our department, all courses that require technical writing follow the same grading rubric. Papers are assessed on nine components, such as experimental methodology, analysis, and presentation quality; each component receives a score ranging from 1 (unsatisfactory) to 4 (outstanding). As a condition for accreditation, ABET (the Accreditation Board 
for Engineering and Technology) requires schools to develop metrics for assessing the quality of instruction. Because technical writing is such an important part of the Ergonomics course, we chose students' performance on the second lab report as one of our self-assessment criteria. We established two performance standards for technical writing in Ergonomics: $70 \%$ of the reports should receive an average score of 3.5 or higher, and $100 \%$ of the component scores on all reports should be 3.0 (satisfactory) or better. In 2009, we were disappointed that only $27 \%$ of the second report submissions received a grade above 3.5 , and only $87 \%$ of the component scores exceeded 3.0. The lowest scores were in the literature review, results, and analysis sections, supporting our qualitative assessment of student performance.

In addition to these technical writing problems, other difficulties arose every semester. Studentseven academic stars - felt overwhelmed and complained about the workload. Team cohesion was slow to develop, and some teams never became functional. Students did not address the graders' comments on their lab reports. The same mistakes were repeated throughout the semester, and the quality of the technical reports was not noticeably different at the semester's end. Finally, and perhaps most disturbingly, some students developed a dislike for the field of human factors. Several cited the labs as the source of their dissatisfaction. One student wrote in a course evaluation that she had expected to enjoy Ergonomics, but after taking this course she wanted nothing more to do with the field.

Repeated problems over many semesters suggested that complaining about the students and their lack of preparation was not going to help. We needed to think like industrial engineers and change the process. In the spring semester of 2010, we adopted a new approach to conducting the laboratory portion of the course.

\section{THE OLD MODEL}

Under the old model, students first attended the lab during the third week of the course. During this session, they received a handout of lab report guidelines and were told to view sample reports in the office. They received a cursory overview of policies and procedures and then conducted an experiment. The full technical report was due one week later. The instructors and teaching assistants were available for consultation during their office hours, but no formal instruction in report writing or data analysis was offered. During the fifth week of the course, the students attended lab for the second time and conducted the second experiment. This schedule was repeated for the remaining labs.

Not surprisingly, the first reports were terrible. It is difficult for an experienced researcher to write a good report in one week; these students were expected not only to write the report but also to learn to use the library, analyze data, and work through the "storming" and "forming" stages of team development in this time (Tuckman, 1965). Furthermore, the process we used to grade the lab reports was time-consuming; students often started working on the second report before they received comments on the first one. Errors that could have been corrected with timely feedback were instead repeated.

\section{THE NEW MODEL}

The new model was developed to address these problems. First, we sought to increase engagement in the lab portion of the course. Second, we used a scaffolding approach to teach experimental methodology and technical writing. Third, we increased the rate and quantity of feedback from the instructor and teaching assistant (TA). Finally, we provided team-development opportunities. Each of these approaches is discussed below.

\section{Increasing engagement in labs.}

The first lab meeting was moved from the third week of class to the second week. Rather than attending labs every other week, students attended each week until the lab portion of the course was concluded. This provided opportunities for scheduled teamwork and more frequent interaction with the TA, who conducted the labs.

\section{Supporting learning through scaffolding.}

During the first meeting, students received basic instruction about technical writing and academic publications. The course instructor introduced the students to academic publications and led them in a 
guided exercise. We hoped that this would help the class better understand the structure and purpose of a technical report. Students perused samples of peer-reviewed journals, conference proceedings, and technical society magazines (such as Industrial Engineer and Ergonomics in Design) and learned about the review and editorial processes for the different types of publications. Using Human Factors as an example, the instructor discussed the structure of a research report. The students then read a peer-reviewed proceedings article (Strayer, Cooper, \& Drews, 2004) and discussed the literature review, methodology, results, and major findings.

One week later, students conducted the first experiment. The following week, they attended lab and brought the results of the first experiment. With guidance from the teaching assistant, they worked together to analyze the results and create a framework for the discussion portion of the report. The same format was followed for the second laboratory experiment.

Under the new model, students submitted the first report in two sections. The first section included the problem definition, literature review, methodology, and references; it was due one week after the experiment was conducted. The second section included the results, discussion, and conclusions and was due the following week. This scaffolding approach (Lajoie, 2005) allowed the students to focus more carefully on each aspect of the report and gave them extra time to seek assistance from the instructor and TA. The report covering the second lab exercise was submitted as a whole, but the class again had two weeks to prepare. The in-lab discussion time provided for the first and second reports helped students manage the workload. The third, fourth, and fifth reports were due one week after their respective experiments were conducted. However, two of these reports were submitted as executive summaries and were therefore not as long as the technical reports.

\section{Increasing feedback rate and quantity.}

Feedback was increased in two ways. Attending lab more frequently increased the amount of interaction between the students and the TA; by guiding the data analysis for the early experiments, the TA could recognize and help the students correct errors in logic and procedure. We also changed the way lab reports were graded. Under the old system, the TA and the instructor both graded the reports, and corrections to the writing were made throughout. This time-consuming process delayed the return of papers. Under the new model, the TA graded the reports as a whole. Following the example of our university's Writing Center, the instructor then selected two to four pages in each report for an in-depth writing critique and noted which pages had been analyzed. This allowed the students to receive graded reports before the subsequent submissions were due.

\section{Providing team-development opportunities.}

OU Industrial Engineering students often work in teams, but they receive only brief instruction about effective teamwork in an introductory engineering course taught during the freshman year. We structured the lab sessions to enhance team development. During the first lab sessions, students and the instructor discussed strategies for effective team-building. The importance of listening was emphasized. Because industrial engineers often work as project managers, we required each lab group to designate a project manager for each report. This person was responsible for maintaining the schedule, delegating responsibilities, and facilitating communication. Since there were no more than five students per team, every person in the course served as project manager at least once. We also encouraged the students to work together in analyzing their results. Holding lab sessions each week provided scheduled discussion time, giving students a few hours during which all group members were available to work together.

\section{ASSESSMENT METRICS}

As a result of our new approach, we expected the following results:

1. Better grades on the second report, as compared with the same report in 2009, with particular improvement in the literature review and analysis sections.

2. Improvement in analytical skills as the semester progressed. 
3. Improvement in technical writing skills throughout the semester.

4. Improvement in team functionality throughout the semester, as indicated by peer evaluations and comments to the instructor and TA.

5. More favorable attitudes about the course, as indicated by end-of-semester evaluations.

\section{RESULTS}

\section{Grades on the second report.}

Overall scores for the report ranged from 3.4 to 4.0 on a four-point scale, and six of the eight groups scored 3.7 or higher. Performance improved over 2009, when scores ranged from 2.9 to 3.8 and only three groups (out of 11) received average scores of 3.5 or higher. Much of the increase can be attributed to improvement in three components. In 2009, low scores were concentrated in the Results (average 3.1), Literature Review (average 2.8), and Analysis sections (average 2.9). Performance in 2010 improved notably in these areas, with average scores increasing to 3.9 for Results, 4.0 for Literature Review, and 3.6 for the Analysis.

\section{Improvement in analytical skills.}

Students' ability to analyze data improved over the semester, rising from about 3.2 on the first report to about 3.8 on the fourth (Figure 1).

\section{Improvement in technical writing skills.}

In 2009, several students remarked in course evaluations that technical writing instruction was needed as a prerequisite. This year, no students remarked on the need for prerequisite writing instruction, and one specifically stated that the course "helped me learn technical writing." Writing quality improved sharply between the first and third reports, with the average score rising from 2.6 to 3.8. Quality declined thereafter, although scores on the final report (average 3.2) were still markedly better than those on the first (Figure 1).

\section{Improvement in team functionality.}

Students evaluated their peers following the submission of each lab assignment. Performance on all of the teamwork evaluation criteria improved over time, indicating that teams generally functioned well (Figure 2). Members of two groups reported problems around the time of the third submission. The improvement in peer evaluation scores after that time suggests that the problems were resolved.

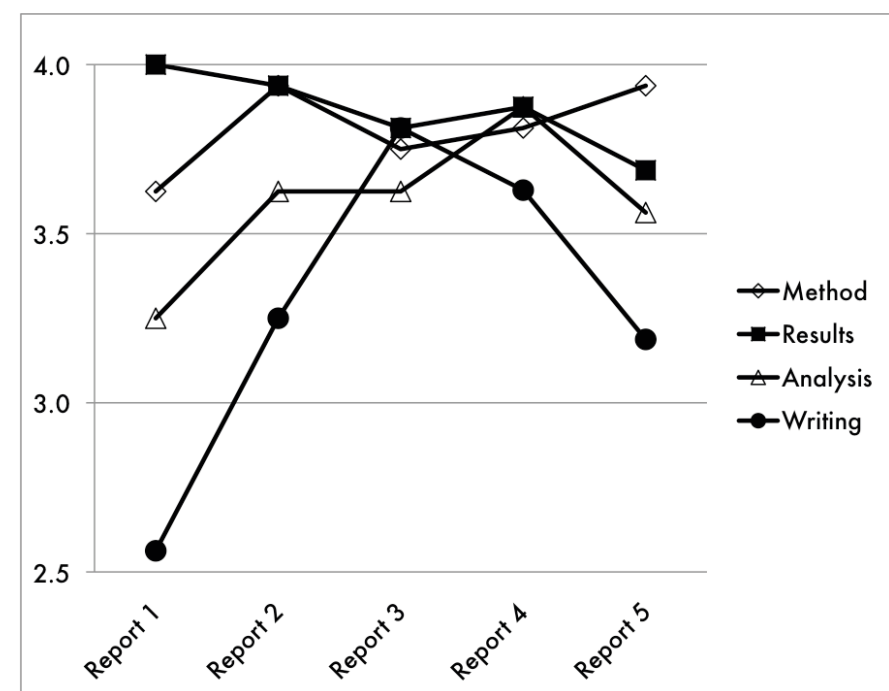

Figure 1. Component score trends.

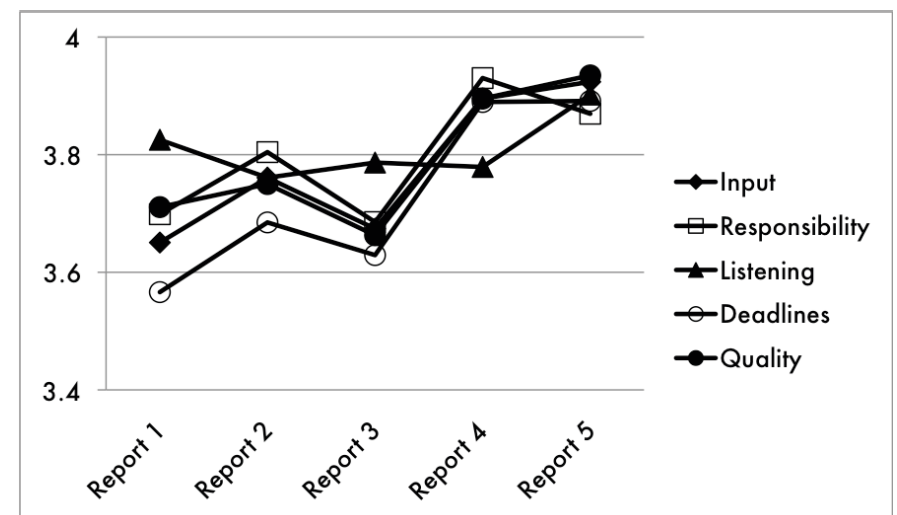

Figure 2. Average peer evaluation of students' contributions to reports.

\section{More favorable attitudes about the course.}

End-of-semester evaluations were used to gauge general attitudes about the course. Overall satisfaction increased from 2.9 to 3.9 on the fivepoint scale used by the College of Engineering. While one student wrote that "I dislike ergonomics [and] have zero intention of going into this field in the future," several others were complimentary. "I wish there were more classes in the department for human factors," wrote one student. Another wrote, "I hope I can take more upper division ergonomics classes, but I wish that this subject had been covered in more detail earlier in the curriculum. It 
seems like a lot of our students are interested in human factors and I think we could retain even more if students were introduced to the human side of engineering early in their college career."

Satisfaction with the lab portion of the course also improved. Students in 2010 were more likely than those in 2009 to say that the lab increased their interest in ergonomics, their understanding of the material, and their problem-solving abilities. Although the amount of required lab time increased this year, students' perceptions that lab time was used effectively rose almost a point, from 3.5 to 4.4 on a 5-point scale.

\section{More favorable attitudes about the field of ergonomics.}

Course evaluations for the OU College of Engineering specifically address whether the course increased the student's interest in the field. In 2009, the average response for this item was 3.5 on a fivepoint scale. In 2010, the average increased to 4.2 .

Three students made inquiries regarding graduate studies in human factors. One of those applied for an international fellowship in the field, while another student requested a recommendation for a summer research internship in $\mathrm{HF} / \mathrm{E}$.

Despite an apparent improvement in students' attitudes regarding HF/E, no students in the Ergonomics course participated in HFES student chapter events.

\section{OTHER DIFFERENCES BETWEEN THE 2009 AND 2010 COURSES}

Of course, the changes in lab structure did not occur independently. Last year, Ergonomics was taught by a two-instructor team, and two TAs conducted the lab sessions. This year, the course was taught by one instructor and one TA. Although both had taught the course last year, the change from team-teaching to individual teaching likely had an effect on both student satisfaction and student performance assessment. The course size declined from 52 to 32 students, allowing the instructor and TA more time for individual interaction and grading papers. Finally, course evaluations were submitted online for the first time in 2010. (In previous years, students had completed paper evaluations in class.) Response rates fell from $65 \%$ in 2009 to $47 \%$ in 2010 .

\section{SUMMARY}

The new approach to laboratory instruction produced positive results. Students' analytical and technical writing skills improved over the previous year and throughout the semester. Although some students complained about the workload, the overall attitude about the ergonomics lab was much better than in previous years. We are pleased with the results and plan to continue refining the course design. Analysis of students' performance and attitudes in subsequent years will show whether these changes result in sustained improvement.

Structuring an ergonomics laboratory course to meet the needs of industrial engineers, who must have an understanding of both physical and cognitive human factors, is challenging. Few resources are available, and laboratory manuals tend to focus on experimental procedures rather than instructional methods and course structures. We hope that this article will inspire discussion of and further research into effective techniques in ergonomics laboratory instruction.

\section{REFERENCES}

Lajoie, S. P. (2005). Extending the scaffolding metaphor. Instructional Science, 33, 541557.

Strayer, D. L., Cooper, J. M., \& Drews, F. A. (2004). What do drivers fail to see when talking on a cell phone? Proceedings of the Human Factors and Ergonomics Society 48th Annual Meeting, 2213-2217. Santa Monica, CA: Human Factors \& Ergonomics Society.

Tuckman, B. W. (1965). Developmental sequence in small groups. Psychological Bulletin, 63, 384-399. 